\title{
Language as a Barrier to Health Care for Oromo Speaking Patients in Hospitals: A Case Study on Jimma and Wollega Public Hospitals
}

\author{
Chimdi Wakuma* $^{1}$; Eba Teresa ${ }^{2}$ \\ Assistant professor Linguistics in the Department of Afaan Oromoo and Literature, Jimma University, Ethiopia \\ Associate professor of Linguistics in the Department of English, Jimma University, Ethiopia \\ *Email: chame.wakuma@gmail.com \\ http://dx.doi.org/10.18415/ijmmu.v6i6.1304
}

\begin{abstract}
A language concordance between doctors and their patients is very important to exchanging information, expressing emotion, instructing patients, and providing health education. But when they are mutually unintelligible because they don't have common language between them, language has become to be a barrier rather than serving at the arena they need it. When language is a barrier, it can interfere with wrong scheduling appointments, hinder the compilation of an accurate medical history, or block understanding of a health provider's instructions and so on and so forth. The aim of this study is to explore language as a barrier to health care for Afaan Oromoo speaking patients in Jimma University Specialized Hospital and Wollaga University Referral Hospital. The study was a qualitative research method and data were collected from patients, patients' family/guardian, and health serves providers through interview method. Focus group discussion was conducted with health service providers and the hospital managements. The findings of the study has revealed that there is no common language between much patients and their health serves providers and/or no professional interpreters between them as well and therefore, the patients and their family or guardians were exposed to delaying treatment, compromising their well-being, leaving the hospital without getting medication being disappointed, and losing their life where the situation is to the worst. It is advisable that if hospitals consider establishing a centralized program and committee with executive level to coordinate services relating to language as a part of the organization's commitment to language sensitive health care. It is better if financial incentives are created to promote, develop and maintain accessibility to qualified health serves and professional interpreters.
\end{abstract}

Keywords: Language as a Barrier; Communication; Interpreter; Health Care 


\section{Introduction}

Studies on language use in hospital-based interactions between patients and health care providers cut across many academic disciplines. Accordingly, sociolinguists could be actively engaged in studying language related difficulties in the medical services delivery system. (Coulmas: 1998:10).

In essence, language is the currency of healthcare. Exchanging information, expressing emotion, instructing patients, and providing health education all occur through the medium of language (Ferguson, 2008). Although we may think that the primary tools of medicine are technological, the most fundamental tool upon which all use of technology depends is language. Language allows patients and health care providers to make their intentions known, a crucial step in the process of identifying a problem, investigating how long it has existed, exploring what meaning this problem may have, and setting in action a treatment strategy (Ferguson, 1966)

A communicative behavior of health service providers is decisive and critical to the diagnosis and treatment of a patient (Hsieh, 2007). Effective communication by its very nature is the successful joint establishment of meaning wherein patients and health care providers exchange information, enabling patients to participate actively in their care from admission through discharge, and ensuring that the responsibilities of both patients and providers are understood. Study results show that effective communication between health care providers and patients is very decisive in providing optimal health care. It has been reported that more than $70 \%$ of the information on which physicians base their diagnoses comes from the history and physical exam of patients and that is realized if the physicians and their patients are able to communicate each other (Alice, H. C. et al. 2005). Therefore, clear communication between the physicians and patient is an obvious requisite for effective healthcare delivery (Breen, 1999). Furthermore, the physicians use language as a means to establish an empathic relationship, which, in itself, may be therapeutic for both parties concerned (Woloshin, et al., 1997).

Therefore, appropriate language services address health disparity issues such as, access to healthcare; increase patients' understanding of medication instructions, procedures, treatment, and appointment visits (Hall, 1998). To be truly effective, communication requires a two-way process (expressive and receptive) in which messages are negotiated until the information is correctly understood by both parties. Successful communication takes place only when providers understand and integrate the information gleaned from patients, and when patients comprehend accurate, timely, complete, and unambiguous messages from providers in a way that enables them to participate responsibly in their care (Alice, H.C. et al 2005).

In another hand, whenever there are communication difficulties between a patient and health service provider due to the use of unintelligible linguistic varieties or non existing interpretation service, the quality of the health service may be compromised. For example, language barriers can interfere with scheduling appointments, hinder the compilation of an accurate medical history, or block understanding of a health provider's instructions (Flores, 2006). In hospitals, sometimes, health care providers respond to their patients in ad hoc ways, for example, by joining up the help of family members, other patients, and staff members such as maintenance and housekeeping staff to act as interpreters for health providers even though they are not trained to act as medical interpreters and mediators between a patient, his/her family, and health care providers. And as a consequence, a physician could make poor diagnosis and/or inappropriate prescriptions. In some unfortunate cases, loss of life can be the final result (Ong, et al 1995: 903).

Sometimes, health care professionals do not consider that it would be their responsibility to adapt themselves to linguistic diversity. If health professionals do not feel a responsibility to adapt, they are less likely to be involved in treating patients' linguistic disparity. As a result, communication related medical errors occur through mistakes in medical history taking, patients' lower obedience to treatment 
because of inability to understand and follow instructions and over-treatment of patients. In the acute care setting, communication failures lead to increases in patient harm, length of stay and resource use, as well as more intense caregiver dissatisfaction and more rapid turnover (Henriksen, 2008).

It should, therefore, be understood that why the essentiality of language services such as the use of intelligible language to the patient is considered to be crucial to language related health services in multicultural and multilingual contexts. Accordingly, Universal Health Care (UHC), equality in coverage and access to health services for all people. However, social policy at the national level cannot be successful without cascading and recognizing it within health delivering institution in regions where the hospitals are situated (Duffin, 1999).

USA, a country with many migrants of the world and who is characterized with linguistic diversity, has developed a national standard guideline on culturally and linguistically appropriate services. The guideline says that health care organizations must offer and provide language services through bilingual staffs and interpreters, at no cost to each patient with communication difficulty at all points of contact, in a timely manner during all hours of operation. It emphasizes that there should be no room for error because of communication in health care that resulted in misdiagnosis, serious drug order, premature death, and overall patient health risks (Egede, 2010).

Therefore, since language is the means by which a patient accesses the health care system, learns about services, makes decisions about her or his health behavior and also the means by which the health care provider accesses a patient's beliefs about health, illness, and creates an opportunity to address and reconcile different belief systems, (Woloshin, 1997), the issue in our hospitals is needed to be studied on how language are a barrier and the solution for the way forward.

\section{Statement of the Problem}

As it was mentioned in the study background, the role of language services in reducing language barriers to health care is very significant. This language service is generally assumed to be given by professional interpreters, bilingual staffs, patients' family or guardians and any available person who knows the languages of both unintelligible parties (the health professionals and patients), when a request comes from the health service providers so as to help patients access to medical care.

Oromia region of Ethiopia is an area where the Oromos, the largest ethnic group with homogenous linguistic nature, are residing. The region has different administrative zones in which Jimma and Eastern Wollega zones are situated in the western part of the region. These two zones have two different public referral hospitals in their respective zone towns. According to evidence found from the hospitals' management and its web page, for example, Jimma University Specialized and Teaching Hospital, currently, is the only teaching and referral hospital in the southwestern part of the country, providing services for more than 15,000 inpatient, 160,000 outpatient, 11,000 emergency cases and 4500 deliveries within a year for those coming to the hospital from its catchment areas like Oromia, SNNP and Gambela regions. In the same manner, Wollega Referral Hospital is saying that it is serving different health seekers from different adjacent zones of Eastern Wollega zones and from Benishangul region. 


\begin{tabular}{|c|c|c|c|c|c|c|c|c|c|c|c|}
\hline \multicolumn{6}{|c|}{ JIMMA ZONE } & \multicolumn{6}{|c|}{ EAST WOLLEGA ZONE } \\
\hline \multicolumn{3}{|c|}{ Residents } & \multicolumn{3}{|c|}{ Afaan Oromoo Speakers } & \multicolumn{3}{|c|}{ Residents } & \multicolumn{3}{|c|}{ Afaan Oromoo Speakers } \\
\hline 苛 & 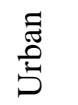 & 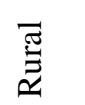 & 胥 & 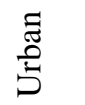 & 菾 & $\stackrel{\overline{\tilde{\sigma}}}{0}$ & $\begin{array}{l}\text { हే } \\
\text { 苫 }\end{array}$ & 范 & $\stackrel{\bar{\Xi}}{0}$ & $\begin{array}{l}\text { 胥 } \\
\text { 菅 }\end{array}$ & $\begin{array}{l}\bar{\pi} \\
\stackrel{\widetilde{\Xi}}{\simeq}\end{array}$ \\
\hline $\begin{array}{l}2.48 \\
\mathrm{M}\end{array}$ & $\begin{array}{l}0.13 \\
\mathrm{~m}\end{array}$ & $\begin{array}{l}.34 \\
\mathrm{~m}\end{array}$ & $\begin{array}{l}2.24 \\
\mathrm{~m}\end{array}$ & $\begin{array}{l}0.08 \\
\mathrm{~m}\end{array}$ & $2.16 \mathrm{~m}$ & $1.21 \mathrm{~m}$ & $0.16 \mathrm{~m}$ & $1.05 \mathrm{~m}$ & $1.06 \mathrm{~m}$ & $0.13 \mathrm{~m}$ & $0.93 \mathrm{~m}$ \\
\hline
\end{tabular}

* The figure is developed from Ethiopian Census data of 2007

In the other hand, numbers of Afaan Oromoo speaking patients who come from both zones and are supposed to be served in both hospitals are worth mentioning here. Therefore, according to 2007 Ethiopian census data of 2007 (the most recent census data available) the total population size of Oromia regional government was 27.15 million $^{1}$ ( $36 \%$ of the country's total population). Of that figure, 3.69 millions are the total residents living in Jimma and Eastern Wollega zones whereas 3.3 million (89.43\%) are Afaan Oromoo speakers. Except 0.21 million (6.36\% of total Afaan Oromoo speakers) residents living in urban area of the selected area, around 3.09 million (93.63\% of total Afaan Oromoo speakers) are living in rural area. To the figure indicating the rural residents, the possibility to find a significant number of residents who are able to communicate in another language other than their own mother tongue (first language) seems difficult. Even though there could be many reasons on the ground for the residents to be monolinguals, they are assumed to be one language speakers who badly need language services for health care purposes whenever they come to hospitals unless the health service providers are able to communicate them through the only language they know.

Therefore, for the provision of safe and consistent health services to the patients and save their precious life from any danger or lose, the researchers believe that the following basic and logical statements have to be the focus of the investigation.

1. The patients, especially those from the rural area, need to access health services by the language they can effectively communicate with.

2. Availability of professional bilingual staffs (one who speak the patients' language) and/or professional interpreters, who either formally hired or voluntarily serving, is very essential so as to help those monolingual patients who come from rural areas to where the hospitals are.

Generally, by this study, how the Afaan Oromoo speaking patients have been served in hospitals so far, what challenges or crisis were they experienced, how the health professionals in the hospitals perceive the existing linguistic disparity, and the health professional requirements procedures were the potential issues to be explored.

\section{The Study Sites}

According to evidences from Jimma University, Jimma University specialized and teaching Hospital (JUSTH) is one of the oldest public hospitals in the Ethiopia. It was established in 1930 E.C by

\footnotetext{
${ }^{1}$ According to the population projection set by Ethiopian CSA (2013), first language speakers of Afaan Oromoo are numbered to be 37.5 million in 2019 , which is $34.5 \%$ of the total population of Ethiopia.
} 
Italian invaders for the service of their soldiers. After the withdrawal of the colonial occupants, it has been governed under the Ethiopian government by the name of "Ras Desta Damtew Hospital" and later "Jimma Hospital "during Dergue regime and currently Jimma 'University Specialized and Teaching Hospital'. Geographically, it is located in Jimma city $352 \mathrm{~km}$ southwest of Addis Ababa. Jimma University specialized and teaching hospital, currently, is the only teaching and referral hospital in the southwestern part of the country, providing services for more than 15,000 inpatient, 160,000 outpatient, 11,000 emergency cases and 4500 deliveries within a year for those coming to the hospital from the catchment population of about 15 million people of Oromia, SNNP and Gambela regions. The hospital is providing more than 19 clinical services with work force of more than 552 nurses (including midwifes), more than 145 residents, more than 21 General medical practitioner, 89 specialized doctors, more than 53 Pharmacist, more than 48 Laboratory technologists, 50 administrative workers and more than 587 supportive staffs.

And Wollega University referral hospital is established in 1932 by Sweden missionaries by the then name Nekemte hospital. It is located in East Wollega Zone, Oromia regional state, western Ethiopia, 331 kilo-meters from Addis Ababa. It was the only referral hospital in the area during the study period and it has got 178 beds. The number of patients getting medical treatment is estimated to be 71,178 for out-patients and 7,108 for in-patients per year. There are four in-patient departments with different disciplines in the hospital: a medical ward, surgical ward, obstetrics and gynecology ward, and pediatrics ward. The hospital has 207 health professionals, when this study was being undergone, with 12 specialists, 18 general practitioners, 68 nurses, 7 health officers, 12 laboratory technicians, 9 pharmacy technicians, and 81 administrative staffs.

\section{Materials and Methods}

This study employs case study approach in which language in communication situation at the selected hospitals have been investigated. It is not the intension of this study to generalize the situation in those selected areas to others hospitals in the country but looking for remedies for communities suffering from linguistic based difficulties.

The objective of this study necessitated a qualitative method of data collection and analysis in order to capture the complex realities of the sociolinguistic situation of the hospital's communication practices. As a main researcher, I devoted to observe the language situation of the hospitals, conduct interviews, make focus group discussions and then interpret the result.

\section{Study Population}

In this study, the patients and patients' family, service providers and their assistants, and hospital management of the hospitals were the population of the study. The study samples were the out-patients and the in-patients who came to the hospitals looking for health services during the data collection. Outpatients are patients who are not hospitalized overnight but who visits a hospital for diagnosis or treatment and in-patients are patients who stays for one or more nights in a hospital for treatment. The service providers include doctors and nurses and the hospital managements are those who have responsibility of administration.

\section{The Samples}

Since the study was qualitatively designed research, samples were selected in purposive. The reason for making the samples selection purposive was to make participants of the study would be those 
who are unable to speak Afaan Oromoo. In the same manner, patients who participated in the study were those whose first language is Afaan Oromoo. Patients who participated in giving evidences were mostly the out patients and their families.

\section{Sources of Data}

Since the aim of this study was to get a deeper understanding of the language situation at hospitals, data had to be collected in more details from primary sources. Accordingly, the data were collected from patients and their families in detailed interview, from health serves providers in open ended questionnaires, and again from health service providers and hospital managements in focus group discussion. University Hospital web pages and empirical studies were also used as secondary data of the study.

\section{Data Collection Methods}

\section{Questionnaire}

Open ended questionnaire was administered to health service providers. A few questions were presented to samples and the questions were left unfiled. The question which very few answered to was saying; "what do you do, if your patient doesn't speak your language".

\section{Observations}

Observation of linguistic situation in a particular area is one of the widely used techniques in sociolinguistic surveys. Observation of language use in hospitals arena is very important technique and this study has used it as the dominating method of data collection. My observation of sociolinguistic phenomena for my study was limited to the hospital environment. I conducted my observe of language use within the hospitals around the registration point, gatherings around examination rooms, queues outside treatment rooms, around emergency room, around patients' bedrooms wards, and the interactions in the corridors of the hospital. Very few data was collected from in-patients when they were having their breakfast. By the reason the health serves providers were not permissive to hear and collect data from doctor-patient conversation in the examination room, farther study is recommended to fill that gap. This study included only the language manner between doctors and their patients; but it was not wider enough to include what the language manner was there around laboratory, pharmacy, and nurse treatment area and so on, therefore, further study is recommendable.

\section{Interview}

It was difficult to collect data from patients and their guardians through questionnaire. Because, it was thought that many of them would not come to the hospital with good mood. They might have tension and anxiety as they may come with of their patient. And sometimes, the patients themselves may feel weak to write information. Therefore, interviewing was the only study tool used in this study. Accordingly, data were collected from informants around registration point, gatherings around examination rooms, queues outside treatment rooms, around emergency room, around patients' bedrooms wards, and the interactions in the corridors of the hospitals.

\section{Focus Group Discussion}

Focus group discussion was conducted at each hospital by bringing together the health serves providers and the hospital managements. The content of the discussion was to examine how the health workers have been using interpreters in the hospitals, issue whether or not health service providers should 
be posted only to areas or hospitals whose languages they speak, and the issue of providing language courses to both local and expatriate staffs in the hospitals.

\section{Ethical Consideration}

Research ethics is an area of enquiry that identifies ethical challenges with a view to develop guidelines that safeguard against any harm and protects the rights of human subjects in research. As researchers, I was cognizant that the study needs to be tested by the issue of ethical principles such as informed consent, beneficence, non-malfeasance, and justice. However, since the overall aim of this study was to identify the mutual intelligibility of patient and health service providers in hospitals, I didn't confronted with anybody while collecting data and the data will be kept confidential except to use only for this study.

\section{Result and Discussion}

\section{Misfortune Situation of the Patients}

The patients were interviewed and they reported on their misfortune condition which they faced because of lack of common language with their doctors and health care providers. The question presented to the respondents was saying, "Do you have any experience of misfortune in which you or your family or your relatives suffered because you and your doctor had no common language? Based on this question, what one patient's guardian, who told me that he came from one of Jimma Zone districts, Nada, narrated was worth mentioning here.

On December 2016, I went to Jimma University Specialized Hospital (JUSH) because my younger son was suffering from injures of gunfire. Government soldiers did it. Arriving at the hospital in the morning about 8:30am, I was told to get into emergency room and wait for a doctor who would come at least after an hour. When the doctor came and saw my son, with other waiting patients in the room, he called for one of the nurses already busy there reading and writing something which we don't know about. The doctor and the nurse came to where my older brother and I were standing waiting for the doctor's visit of my son. He talked to me in a language which my older brother and I couldn't understand of it by then and we didn't say anything. Following his talk, the nurse uttered something in the same language the doctor used and yet we responded anything. Latter, the doctor went back talking with the nurse and left the room. Following from the back, I talked to him in the only language I know, Afaan Oromoo, and attempted to narrate him what happened to my son saying; is that fair; is that justice that I and my son dying because we don't know Amharic; but any of them was turned back to respond to my pleading .

My son was shouting and calling for any help of doctors. He, too, was a monolingual; speak only Afaan Oromoo, and none of us was able to speak the language our doctors speak; Amharic. After half an hour, the nurse back and told us to wait for a while for the doctor but the doctor didn't back until 3:00pm. Hoping that the doctor would come back, I was encouraging my son to have endurance to the pain he was suffering of it. However, the doctor went to see other patients and he treated a case of three patients. By that time, I had got a deep anger but I self-convinced to cool down and be tolerant. Finally, the doctor came around 4:15pm and started to talk with my son in Amharic. As my son couldn't understand Amharic to respond to him, he continued his shouting calling for a help. The doctor looked at the injured body of my son, which was around down of his belly, and then he started writing a drag prescription for us. While giving me the prescription, the doctor was talking in Amharic to others standing around saying; unless you 
come with the language your physicians are here to serve you, it will be impossible for you to be cured; this is federal institution and we are not obliged to learn languages of every patient. One of the people standing there told me what the doctor said and I left out with my son and my older brother in the evening. I bought the drag the doctor ordered and went back home. Unfortunately, my son didn't survive and passed without any medical treatment. Today, I came again after a year for medical treatment for myself and fortunately found a doctor serving me in the language I know. That is good. After the man completed telling his story, no more questions were presented to him as he was so emotional and too hot. /JM, IN6, 2017/ (transcribed from Afaan Oromoo recorded audio)

What one can understand from this story may be different based on the readers focus. The whole story narrated by the patient's father was heartrending and potentially was triggered by serious language unintelligibility realized between the patient, patient's family and the health service providers. In essence, intelligible language is very important between doctors and patients to exchanging information, expressing emotion, instructing patients, and providing health education. These all were not possible between the doctors and the target patients in the hospital. In the story, even though the patient's ill-fate was losing his life, there were also other discomforting happenings that the patient and the patient's family was tempted by and which is also likely to be realized in life of others' who may share uncommon language with their doctors. Some of the happenings were:

\section{A) Patient's delaying of treatment}

If the patient and the doctor had understood each other either with common language or through interpreter in facilitating the health care serves in the hospital, the tragedy would have not come to the life of the patient. But, by the fact that there was no common language between the patient and the health care providers and no interpreters as well, the patient and his family were exposed to delaying treatment. To consolidate that, a study conducted in the United Kingdom, found that due to language barriers members of ethnic minority groups did not access healthcare services until their health problems became serious and life threatening (Gerish et al., 2004).

\section{B) Compromised Patient Well-being}

The language barrier has made the patient to compromise his 'well-being since he was less likely to receive his well-being by his language. Since the patient and his family were facing language barriers, it was less likely to receive an accurate diagnosis, follow the doctor's advice and adhere to any medication schedule. The impact on the patient well-being has also been found when looking at adverse events. Adverse events are any unintended harm to the patient by an act of commission or omission rather than by the underlying disease or condition of the patient (Buwalda, 2007). Therefore, it can be a point of debate that the death of the patient was come from the already sick condition of the patient.

C) Discomfort and sense of grievance the doctor developed on the patient

The doctor had not used interpreter to help the patient and as a result he was emotional when uncomfortably uttered wrong conclusion about language use. On such situation, the doctors are often unlikely to perceive language disparity as part of the institution's inability to treat the patients or as their own limitation of inaccessibility to the patients' language, but they leave it aside as patients' concern. Because, they blame that the patients should have known the language of their doctors as that language is supposed to be language of wider communication. And also they believe that patients sometimes deliberately do not understand what the doctors are saying. On the other hand, the patient's family, the father, was in sense of grievance as he assumed that his son was lost because of poor treatment of the doctors. 
Reception room was one of the areas of language related problems in the hospitals this study has been undergone. Patients and patients' guardians are particularly frustrated by language barriers in admission procedures matters. In JUSH, patients are complaining that staffs members who are working in the reception section are not respectful and some of them treated patients rudely because of their inability of Amharic language; and some of them even try to tell them to go and learn Amharic. According to the interview with some disappointing patients who were standing at the front side of the reception room, even bilingual workers who serve in the reception room are not willing to serve in patients' language even though they know the language very well. One of the patients said:

I came from one of the Jimma zone districts, Shabe, to this hospital half an hour ago. As soon as I arrived here, I was directed to this place to get registered and so that would be admitted to the hospital. But some of the workers in his hospital are not polite enough while registering patients. I heard when one of the workers was nagging with another person being registered here because of the patient said to him 'I don't understand Amharic. And finally the service provider said to him 'go away with your language'. IJM, IN4, 2017/ (transcribed from Afaan Oromoo recorded audio)

A few in-patients, whom I talked with them while they were talking and drinking tea with their guardians in WURH, have reported that language interpretation for them is badly needed in the hospital especially during patient history taking when the doctors are not speaking Afaan Oromoo. As their statement, there were many chances to be treated and visited by Afaan Oromoo speaker doctors. At that time, there was sometimes a possibility to be bypassed without being seen by doctors. According to the informants, the Afaan Oromoo speaker doctors in the hospital are using both as a professional person and a language interpreters. And there is serious delaying of patient treatment where the language disparity is there between the doctors and the patients. Or, for the doctors, there may be a possibility of using any persons who they don't know to serves as interpreters only just for that moment. Patients said the followings:

They have no interpreters to support patients who don't able to communicate in Amharic. But there are chances to be treated and visited by Afaan Oromoo speaker doctors. For example, I have taken an appendix out surgery by a doctor who doesn't speak my language. First when I arrived to the hospital with a very painful and a serious inflammation of my abdomen, my doctor was there but he didn't visit me for almost 9:30am-2:00pm. Because, first he came and talked to me in Amharic and realized that I am unable to communicate him in it. But, he was not willing to use any person with me and around me as an interpreter for the reason, he told me latter, that he doesn't accept it professionally and to make medical caution. Finally he came with a doctor who can speak Afaan Oromoo and used him for communicating me. Having completed the medical diagnosis, the doctor has made to me the surgery successfully. Then, I was being visited by many Afaan Oromoo speaker doctors many times. Now, I don't have any problem. . INK, IN4, 2017/( transcribed from Afaan Oromoo recorded audio)

Another patient from the next bed talked following him:

Some doctors do not speak Afaan Oromoo, but they always use any person as interpreter to communicate me. Whenever I do not understand what he (my doctor) is saying, he (himself) would search any person who can communicate in both Amharic and Afaan Oromoo to interpret. /NK, IN5, 2017/ (transcribed from Afaan Oromoo recorded audio)

In addition, according to evidences from some out-patient's parents sitting in the waiting room of the hospital, there is no interpretation service given by using either doctors or nurses who know Afaan Oromoo; but by any person sitting in the waiting room and knows the language of the doctors. Although 
some patients are not opposing such interpretation service, some others are uncomfortable to have a stranger person to be involved in their personal secrete as they feel that their health situation has to be kept secret. One woman who has brought her daughter to the hospital said this:

There are times that I feel uncomfortable to tell someone everything that is going on my daughter. My daughter, too, is not willing to tell her all personal cases unless to me and may be only to the doctor. I believe that her problem should be told only to the doctor. And I asked her, "What would you do then?"She replied; in case we are unable to find a doctor who communicates us in Afaan Oromoo, we may go out to search for a convenient doctor for us. /JM, IN5, 2017/(transcribed from Afaan Oromoo recorded audio)

Some patients who have come to the hospitals demanding health service were totally mute to Amharic, the language of some health service providers. Unless they are communicated in Afaan Oromoo either through bilingual doctors or interpreters, the possibility for them to hear or to tell about their diseases would be difficult. In a situation like this, patients are forced to take their medication for grant even without their consent where actually it needs or they may leave the hospital without any medication. I met with a mother leaving from emergency room and was murmuring. I asked her whether her daughter is getting better. Then she replied; how can I know whether my daughter has got better without talking with doctors? I asked what the reason for the silence was. The mother said; my language. She explained:

I did not know what they were doing... They were speaking, but I did not know what they were doing because I don't speak Amharic. I did not understand. The only thing I noticed was that they couldn't find a vein to take blood and therefore, my daughter was suffering a lot with dry needling. Finally I detached my daughter from their hand and now leaving. /JM, IN3, 2017/ (transcribed from Afaan Oromoo recorded audio)

In JUSH, a man who I found at the gate of emergency room looks unhappy when waiting for medical services. The man was very disappointing with the disarray crowd around the emergency room and therefore he was noisily complaining. A doctor who was bypassing on the front side where we were standing saw the man and asked him in Amharic whether there is anything happened to him to complain differently. He stepped carrying his child to where the doctor was and replied to him in his poor Amharic. After they stopped their conversation, I asked the man what the doctor told him about his child. But the man replied, nothing. I continued, why? And he said:

If I am going to take my child to the doctor, it's because something important. So I need for the doctor to understand what I want and I want to understand what he is saying. But if you are talking to doctors, they don't understand what you are saying; maybe they understand half of the things we are saying. You don't understand what they are telling you about all your medication, and then they get upset because you tell them that you don't understand their language and therefore you need interpreters and they tell you there's none. IJU, IN2, 2017/ (transcribed from Afaan Oromoo recorded audio)

After his explanation, I wanted for more clarification and asked him again saying, do you mean that you didn't understand what the doctor was saying to you? The man replied;

Sometimes it's very upsetting when someone is telling you something, and you don't really understand him. You understand a few words and you hope that what you've heard is correct, but you are not really sure that you understood all the information given to you, unless there's an interpreter there that can tell you exactly what's being said. IJU, IN2, 2017/ (transcribed from Afaan Oromoo recorded audio) 
The man was very emotional. The absence of interpreters in the emergency room has made him to be distressing; may be due to the nature of the medical urgency needed there. The man continued:

Sometimes they say something and I respond yes, but I know I did not understand. It just seems that sometimes you hear a word that makes sense. You think you understand the word but you don't. Most often I want to hurry-up and finish, because I don't want them to see that I don't understand. /JU, IN2, 2017/ (transcribed from Afaan Oromoo recorded audio)

While the man was talking to me, the doctor who had been talking to him came and invited him to enter with his child. Then, the man came back after almost ten minute stays with the doctor and I approached him to know the condition of his child in the room. Thus, I asked whether his child is getting better. The man replied:

An interpreter was never provided to me in the emergency room; I hoped I would have another person who understands Amharic and Afaan Oromoo better than I do to accompanies me, but I did not have an interpreter. It was difficult ... because I wanted to tell the doctor something specific that I saw in the child, but I end up not telling him everything because he doesn't speak my language. There are some things that I do not tell him, because I cannot explain it well enough. /JU, IN2, 2017/ (transcribed from Afaan Oromoo recorded audio)

While going from one zone to another zone in the building of JUSH, I came across to Gera zone where the ward for ENT (eye, ear and throat) medication is taking place. Many patients and their guardians were seen there being crowded. I approached to a young boy whose age is may be around 1618 and I asked him what the crowd is for. The boy explained me that the gathering is for ENT treatment and the doctor is a resent new comer foreigner from Cuba. Latter, I realized that the foreigner doctor who is a specialist in ENT medication is delivering serves with two Ethiopian doctors. The two Ethiopian doctors are unable to communicate in Afaan Oromoo, as the evidence from the served indicates, and therefore, there is no room for Afaan Oromoo speakers to have any conversation either with the Ethiopian doctors or with the foreigners. Therefore, patients who were unable to speak Amharic language were exposed to be delayed medication, extra medical cost, increase the risk of misinterpretation of language and symptoms and in effect increase the risk of over-diagnosis or inaccurate diagnosis and returning home without knowing once disease type and without knowledge for alternative treatments.

There was a nurse talking to the patients to sit according to their medical card number order. But what practically observed there was that different doctors and health care providers were coming and entering into the ENT treatment room with selective patients one by one. I asked one patient standing on my side that why patients are not entered into the room according to their card order. The patient talked to me emotionally and said:

This medication (ENT) is given only twice in a week (Tuesday and Thursday). I came on Tuesday morning to this hospital and I went back to my rented bed in hotel without any medication. The reason was that what you are observing now. We have a medical card number given us by the nurse in the office next to their office. But, either any other doctor or nurse or any staff member come and take one of the patients that he/she knows with him/her and enters into the room. This is the norm being practiced in the hospital especially at ENT ward. Again I came today (Thursday) with my ear problem and observing their usual drama. I don't know where to go and tell the problem. I don't know Amharic and the nurse who gave us the card doesn't know Afaan Oromoo and therefore no communication between us. She herself sometimes take one two patients as she likes. IJU, IN7, 2017/ (transcribed from Afaan Oromoo recorded audio) 
In the meantime, a man who had gone to buy what has been ordered for his wife medication returned and opened the door of the room; and started to shout at the doctors. He has gloves, syringes, glucose, and medicines at his hand which he bought according to the prescription by a doctor. The prescription was given by one of the Ethiopian doctors in the room. And the man self-questioned on what is the use of the things he bought for in treating his wife's ear problem and he asked for the pharmacist who spoke to him in Afaan Oromoo. The pharmacist advised him to go back to the hospital for identifying the confusion. The pharmacist had already given him a clue that all the things he bought are not important for the very condition of his wife. When I saw that the man is talking to the doctors emotionally but the doctors do not understand his language, Afaan Oromoo, I interfered and said to the man to calm down and asked what his case was. The man said the following:

This is my third day in this hospital. My wife and I don't know Amharic to tell precisely the symptoms of my wife's condition and they (the doctors) don't know Afaan Oromoo to tell us about her sickness, important caution to be taken and the instruction for medicine use. My wife and I were here an hour ago. We didn't tell anything to our doctors and they did so to us for all our problems were our language. They don't know Afaan Oromoo and we do so Amharic. Finally, this doctor, (pointing to one of the Ethiopian doctor), gave me this paper (medicine prescription) and sent me out. Then, I bought these things and came back. Let him (the doctor) tell us what the use of it and how can we use it and you help us in interpretation. Finally the doctor said sorry for the wrong prescription and the foreanier doctor left the room disappointing with the event. IJU, IN2, 2017/ (transcribed from Afaan Oromoo recorded audio)

\section{Health Professionals Linguistic Disparity Outlook against Their Patients}

From the open-ended questions that the service providers responded to, the question that saying, 'what do you do, if your patient doesn't speak your language?' has got much attention by respondents. To that question, many have responded in detail with examples and here presented are among the selected responses given by the non-Afaan Oromoo speaker health professionals.

\section{Example 1;}

This respondent is a doctor in Jimma Specialized and teaching Hospital. According to the evidence found from personal information section of the questionnaire, she can speak fluently five Ethiopian languages and among them walaita language is her mother tongue/first language. The doctor first put her stand that doctors need to know the languages of their patients. She supported her statement with other country's experience that she had learned. She started her response saying,

“...I was outside Ethiopia for a while for short term training and I had a chance to see the situation of language use in a hospital. When I was there, Lithuania, many foreign health professionals were busy in learning Lithuania as the state policy asked everyone to be able to speak Lithuanian as a state language."

She added,

"Most doctors of the hospital can speak Russians which they learned with own personal initiation to serve their patients when they are Russian speakers. And what was unquestionable there was knowledge of English as it was mandatory to serve patients from all over the world".

The doctor has been serving in JUSH and therefore she must faced different linguistic disparity problems in her stay. In resolving such linguistic disparity problem, she proposed and has been practicing the interpretation serves very often. As the interpretation instrument sometimes she used to any Oromo 
language speaker available around to help her as an interpreter and most of the time, she has been using her colleagues who speak Afaan Oromoo. The following is her written text:

"In the past of my service age, there were many chances that in which I met patients who do not speak any of the language that I speak but only Oromo language. In that circumstance, sometimes I have been using any Oromo language speaker available around to help me as an interpreter. If doctors and health service providers are from other linguistic and cultural community, I know that they face both linguistic and cultural related problems when they go to other language speakers. We, the health professionals, also believe that the interpreters could break some intimacy which is needed especially when dealing with mentally ill patients. The most important thing and what some health professionals are discussing very often is employment of professional interpreters. By the fact that all the Ethiopian privates and public hospitals have no that tradition, I used to have help from my colleagues of Afaan Oromoo speakers to interpret in case it was not impossible for them to do so. Even though I am not quite sure that I didn't harm any of my patients because of his/her language, I don't remember days in which I felt guilty of my patient as he/she was harmed because of his/her language. Therefore, it is very important for a patient to get services either in his or her own language for healthy health care service or to be served through professional interpreter. /Q9, JIM-DOC/

Example 2

One of the doctors, who mentioned that he has been serving in Wollega University Referral hospital, has responded that the use of interpreters is damaging and risky in the process of delivering health service. According to that doctor, health care providers have to serve their patients in the language the patients understand. If they are not speaking the language of their patient, they have to take a measure to learn it for the sake of serving their patients holistically. In making his belief practical, the doctor has mentioned that he learned Afaan Oromoo by his own effort to serve the Afaan Oromoo speaking majority patients in wollega university hospital after he lived there for six years. Even though the doctor believes the vitality of learning patients' language in order to deliver successful health service, he didn't totally denied the contribution interpreters can have where there could be a possibility of total incomprehensiveness between health care providers and the patients. But the doctor again underline that the interpreter has not to be any person but a professional one. if one argue that utilizing family members or personal friends is not unappreciative or disregarding in the effort they have put into the welfare of the patient, but an important part of medical practice to be ensured and to make the patient is getting the best unbiased health care provided without extra barriers, the interpreter is needed to be as someone who speaks the same language as the doctor. The following is the text written by the doctor.

I personally appreciate if physicians able to serve their patients by using the language their patients can understand. Unfortunately, I know only two languages, Amharic (my first language) and English. But when I learned that I am serving most of Afaan Oromoo speakers in this hospital, Wollega Referral Hospital, I decided to learn Afaan Oromoo by myself after living for six years in the town Nakamte and therefore, I can now understand what my patients say to me even though I am not fluent speaker of the language. On the other hand, I don't believe that doctors and patients need to understand each other through interpreters. Because, if the interpreter is only a fair speaker of the target language but a strange to medical terms, the possibility for misinterpretation to take place between the interlocutors will be predictable. Regarding to this issue let me forward you a witness that I have got from what I read. A number of years ago a doctor was asked to provide general anesthesia for a visiting Iraqi soldier who presented with an acute abdomen requiring an emergency laparotomy. The patient had no understanding of the English language and a qualified interpreter could not be found within the 
time available. Fortunately he was accompanied by his commanding officer who was well educated and spoke excellent English. The officer also speaks the language of the soldier. Exchange of information was polite, easy and efficient with interpretation. However, the statement of the doctor to the patient was there are risks, including a small risk of death; unexpectedly resulted in nothing more than a nod of acceptance from the officer. The doctor needed the soldier to understand that there is a risk of death. He repeated. But that was not a problem for him. Eventually, one of the doctor's colleagues who can speak the language of the patient unexpectedly arrived and helped the soldier to understand the doctor and therefore rebutted his consent. The doctor said, from this story, I learned not to trust the interpreters. IQ4, NAK-DOC/

\section{Health Professionals' Experiences in Using Interpreters in the Public Health System}

Informants who participated on focus group discussion at both public hospitals have made an extensive and detailed discussion on the issue of utilizing interpreters in the healthcare services. The aim of the discussion was to examine how the health workers have been using interpreters in the hospitals. The informants who participated on the discussion are doctors, nurses, and the hospitals' middle managements. Normally patients who don't understand their physicians"' language may need interpreters for communication. Interpreters should be provided at important points during healthcare, such as when discussing medical history, treatments, test results, diagnoses, during admission and assessment, and when they are required to give informed consent. But what generally understood from the discussion was that the use of interpreters is not a method that is sufficiently fixed in health care as a standardized and quality-assured procedure. But such use is incidental and dependent on the health provider's own knowledge, good will and initiative.

One of the doctors in JUSH, who clearly mentioned that he is Afaan Oromoo speaker which he learnt after his coming to Jimma explained that most of the doctors and other health services providers in the hospitals are not motivated to use language interpreters even where the patients are totally mute to understand their doctor's language. According to this doctor, language interpretation is a very vital instrument where doctors and their patients have no common language among them. His statement was the following;

Health-care workers of this hospital often do not want to use interpreters rather they prefer to speak in Amharic if ones they observe that the patient is trying to speak Amharic even when he/she is unexpressive in it. But, if one attempt to speak any language, it is clear that it doesn't mean he/she is a speaker of that language. First our doctors initiate conversation in the language they know without knowing the sufficiency of the patient's listening and speaking skills of the language. Then the patients are observed straggling to use the language first the doctor used even if they are not able to communicate in it. /JU, FG, N3,5,/

According to a doctor who added a support idea on using interpreters for health service provision, sometimes patients often blame themselves for not speaking a doctor's language proficiently and often feel ashamed. Sometimes, they do not admit having language difficulties; instead, they pretend to understand. In that manner, if the health situation of the patients is the acute one, it might be resulted in life-threatening conditions. Therefore, it is better if health serves providers work towards assuring the well-being of their patients by addressing the linguistic problem may exist between them and their patients. The statement is the following:

Our problems are our attitude and our level of commitment to serve our society. Because, when we first come to visit our patient, we don't ask and possibly want to know what language our patients listen and speak fluently. Our patients, who are in need of our sympathy, may pretend as if they understand our language where the reality is not. 
Therefore, if we don't have care for language based tiny like problems, it may be a cause for more serious problems to our patients. /JU FG, N1,4/

The doctor added; the patient's medical record card which serves to provide information about patients' identity is an indication that the system in the hospital neglects the language issue of patients at institution level. Both the Jimma University Specialized Hospital and the Wollega Referral Hospital medical card record system includes a space for recording a patient's name, age, sex, address and phone number (optional) only; it does not include information like patients' language knowledge and the proficiency level. And those data on medical record card collected during initial assessment are used only to relate medical case only. Therefore, the doctor recommended that all health serves providing professionals have to have sympathy for their patients anyway.

If we actually want to treat language related problems of our patient, simply we do act to review the content of the patient's medical record card which first filled at reception room and sent to a doctor. /JU FG, N1, 4/

Ideas raised and discussed by the participants were not all uniform and certain. Some of them were arguing that there was no interpretation problem in the hospital while others blame stressing that the problems exist. One of the doctors in the discussion said being with emotion;

I think it is better if we don't bring every health care provider under similar level; I also would like to advise each of us not to generalize things to their worst part. I have been serving in this hospital for at least seven years and I know that doctors use interpreters when they meet with patients they don't know their languages. Actually they do that where the hospital is not forcing them to do so but for the sake of their professional commitment and the well-being of their patients. But when a doctor observes that patients are trying to communicate him/her in Amharic, then, they use the language. //JU FG, N2/

The doctor confirmed the idea which has already risen that doctors initiate the patients to speak the health providers' language and proceed with it if once they observe that the patient is trying to speak the doctor's language even when the patient is insufficient in that language. But he talked in contrast to the idea that doctors totally don't use interpreters. A question was forwarded to that doctor, what types of interpreters are being used and do you think that that is effective to deliver quality health serves?

The doctor replied;

actually Ethiopians health centers and hospitals has no professional and employed interpreter rather health care providers use any nearby available individual whether they are family member, staffs or any other individual who can understand both the care provider's language and the patient's one. Sometimes, the health care providers search for those individual working in the hospital and talking that language if they are available and willing to interpret that language. /JU FG, N2/

\section{Language and Health Service Providers Posting}

On the FGD, a question was raised whether or not health service providers should be posted only to areas or hospitals whose languages they speak. The question was asked with the aim of finding out whether the posting of health service providers should take into consideration the facilitation of communication between patients and their service providers. In response to the question, two categories 
of respondents were observed. Some participants were very firm in their support for a staff posting policy that takes into consideration the language factor. Because language as a means of communication is a very important tool which is supposed to be considered. Yes, the person has been trained but is he going to deliver knowledge or skill in terms of language? Where we have got language problems, I don't think that we can deliver it or we might deliver but the consumer of our serves may not be satisfied. Among those who recommend that health service providers should speak the language of their patients, the statement by one specialized doctor who had been serving the hospital as the hospital top management is presented here:

The posting of health service providers should take into consideration an individual's competence in the language(s) of the new duty station. Such a perspective would ensure that there is efficient communication between service providers and their clients since linguistic barriers to communication would have been greatly reduced due to the use of a common language. Not only the patient who benefits from that form, the service provider also would be able to discharge his or her duties more efficiently than is the case when he or she has to use interpreters. IJU FG, N6/

Many of the participants forwarded their personal opinion on the issue that posting staff on the basis of their linguistic competencies means that civil servants work in their home district or region. This could promote regionalism and ethnic loyalties at the expense of national unity. The idea of working among "my own people" with whom one shares a language is not seen to be politically healthy as a service provider has to care for anyone regardless of color, religion, language or race. This is a pointer to the importance of non-discriminatory practices in healthcare delivery. They argued that health service providers are not be judged only by the language they use to serve their patients. They may learn the needy language and/or they may use interpreters to fill the language related gap. But their existence in the hospital is more valuable than the problem that we have raised. One of the service providers who told that he was a student of JUSH and now a specialized doctor since 2013 in the hospital said that he is so frustrated with the language situation at the hospital. And he emphasized that he is on the verge to leave the hospital. And he mentioned language disparity with his patients as an attributing factor for leaving. He stated his reflection as follow:

JUSH is a federal institution in which doctors and other staff members shouldn't have been forced to know the local languages they don't know, rather the hospital management and we all (doctors) must have encouraged the clients to learn the widely spoken language of the country (according to him the Amharic). But, the language situation in the hospital looks more of an agenda of politics and a cause to make differences. Therefore, the idea about posting health professionals based on their linguistics competences has to be stopped before it goes long. /JU FG, N7/

Some participants also forwarded on points which they brought as ground for the rejection of the proposed posting strategy that it could not be practically implemented. There is no guarantee that each linguistic zone would have enough qualified personnel. The strategy would mean some areas would have more personnel than others. In that sense, some region can be flooded with professional whereas the other regions could be understaffed.

The fourth argument was that such posting would mean that civil servants would be tied to one region for their entire length of duty, thus limiting their freedom of movement. It was felt that the current flexible posting of staff enabled civil servants to experience life in different parts of the country. In the process, the civil servants also learnt new languages. Others said they would not like to work permanently in their home districts for fear of being disturbed by relatives from the extended family who seek various forms of assistance. The fifth argument was that the linguistic situation in Malawi was not so complex as 
to warrant such a posting policy. The sixth argument was that the existence of lingua francas such as Chewa, Tumbuka and even English, dismantled some of the linguistic barriers to communication. Service provider 8, (a clinician) for example, observed that: "As a country/nation, we have a national language which is widely known and as part of the world, we are blessed with an international language like English." Another argument was that being posted to different area enables a service provider to undergo different clinical experiences. Such enrichment of professional experience cannot be adequately achieved if a service provider is confined to one duty station. For example, the state-of- the-art medical equipment that is available at the $\mathrm{MCH}$ is not available at other hospitals. By being posted to the $\mathrm{MCH}$, one therefore has a chance to experience using such equipment. The overall majority view was that Malawi already has an acute shortage of health service providers, and adjusting the posting of staff on linguistic grounds would only worsen the situation.

\section{Language Courses for Health Service Providers}

Having the intension that if service providers are provided with patients' language learning access, there would be a possibility to them to learn the language and therefore a question about it was presented to the discussion. Some service providers of the hospitals suggested that one way of reducing the linguistic barriers at hospitals is to provide language courses to both local and expatriate staffs. Such courses would improve the communicative ability of the service providers as they discharge their duties. Accordingly, there is no doubt that knowledge of Afaan Oromoo by a service provider would greatly reduce his or her linguistic barriers when communicating with patients. The selection of Afaan Oromoo as the language to be taught to the hospitals' service providers is similar to what scholars call the pioneer missionary model of language learning. According to this model, pioneer missionaries always learnt the dominant language(s) of the area they were working in. Therefore, both local and expatriate service providers can take Afaan Oromoo courses. In the discussion, there was divided opinion on the importance and relevance of these courses for expatriate health service providers. Of the doctors one who support on the expatriate doctors to be taught local language said,

When a doctor speaks no local language, patients do not feel that he/she is part of them. This is an important point, especially as it comes to an expatriate doctor. /JU FG, N8/

Indeed it is true that the language one chooses to speak brings him/her either closer or further away from the people one is working with. Speaking a common language with one's patients is a positive face sub-strategy, because people may feel that they have a language which even foreigners find worth learning. Perceptions vary, of course. Some people welcome foreigners who attempt to learn their languages whilst others do not.

In addition, one of the doctors said the following to confirm the issue on discussion;

\section{"If I know the language which patients use, I can find their problems easily and immediately."}

This is indeed true. Such a service provider does not have to waste time searching or waiting for an interpreter. Knowledge of the patient's language enables a service provider to avoid most of the problems that come with interpretation. Knowledge of patients' language helps to get a more accurate patient history, thus reaching accurate diagnosis easily and saving time and money. Indeed time is wasted while looking for interpreters. Another reason for service providers' desire to speak the language(s) of their patients is the creation of a communicative climate that is conducive to the building of good relationship.

Few of the participants were not happy with the majority idea that the foreign doctors have to be taught the local language. They argue that these doctors may perceive such requirement as an additional burden to their service which they may get of it as a frustrating factor. 


\section{Conclusion and Recommendation}

\section{Conclusion}

In essence, language intelligibility is very important between doctors and patients to exchanging information, expressing emotion, instructing patients, and providing health education. But, according to the complains of different sample patients when interviewed, by the fact that there is no common language between much patients and the health serves providers and/or no professional interpreters between them as well and therefore, the patients and their family or guardians were exposed to delaying treatment, compromising their well-being, leaving the hospital without getting medication being disappointed, and losing their life where the situation is to the worst. Accordingly, language has come to be victimizing barrier for Afaan Oromoo speakers in the JUSH and WURH.

For the difficulties they were facing, many patients and their families were blaming their doctors for they are unable to speak their patients language and some others were dissatisfied with communication between themselves and their doctors, tending to blame their own linguistic limitation rather than that of the doctors. Therefore, the provision and use of interpreters could alleviate these barriers. And doctors should be encouraged to learn greetings and basic communication in indigenous languages

Sometimes, there was a case of interpretation service given by using neither doctors nor nurses who know Afaan Oromoo; but by using any person sitting in the waiting room and knows the language of the doctors. Although such practice is not need to be totally opposed, some patients are uncomfortable to have a stranger person to be involved in their personal secrete as they feel that their health situation has to be kept secret.

There is no doubt that collaboration needs to play a role in helping hospitals have their own professional interpreters. For example, as hospitals develop language related organizational policies and procedures; leadership should engage and bring together stakeholders from multiple departments in order to understand the environment (supports, constraints, etc.) In which current procedures are being carried out.

\section{Recommendations}

- Hospital should consider establishing a centralized program and committee with executive level reporting to coordinate services relating to language as a part of the organization's commitment to language sensitive health care. Financial incentives should be created to promote, develop and maintain accessibility to qualified health care interpreters.

- Hospital should have its own professional interpreters or translators to facilitate communication and have trusted quality of data. 


\section{References}

Alice H. C. etal. (2005). Addressing Language Access Issues in Your Practice. California Academy of Family Physicians; Modesto, California and Basic Support (JABS), and the media. Swindon: ESRC.

Breen, L.M. (1999). What should I do if my patient does not speak English? Journal of Medical Association, 282, 819. doi: 10.1001/jama.282.9.819.

Buwalda, H. (2007). Basic competencies for mental health interpreters. Retrieved May 2018 from: www.asylumsupport.info/publications/mlshs/mental health/htm.

Coulmas, Florian (1998). "Introduction." The Handbook of Sociolinguistics. Coulmas, Florian (Editor). Blackwell Publishing house.

Duffin J (1999) History of medicine: a scandalously short introduction. London.

Egede. (2010). Center race, ethnicity, culture and disparities in health care. JGIM MedicalUniversity of South Carolina Charleston, SC, USA.

Ferguson, C. A. (1966) “On Sociolinguistically Oriented Language Surveys.” The Linguistic Reporter: Newsletter of the Centre for Applied Linguistics. Pa. (1-3).

Ferguson, W.J. (2008). The benefits and perils of knowing "a little bit" of Spanish when communicating with Spanish-speaking patients. Health Affairs, 27(6), 1695- 1700.

Flores, G. (2006). Language barriers to health care in the United States. The New England Journal of Medicine, 355(3), 229-230.

Gerrish, K., Chau, R., Sobowale, A., \& Birks, E. (2004). Bridging the language barrier: the use of interpreters in primary care nursing. Health and Social Care in the Community, 12(5), 407-413.doi: 10.1111/j.1365-2524.2004.00510.

Hall C (1998) Vaccination may trigger disease linked to autism. The Daily Telegraph, 27.

Henriksen K, Battles JB, Keyes MA. Improving patient safety through provider communication strategy enhancements 2008 .

Hsieh, E. (2007). Interpreters as co-diagnosticians: Overlapping roles and services between providers and interpreters.Social Science and Medicine, 64, 924-937. doi: 10.1016/j.socscimed.2006.10.015.

Woloshin, S., Schwartz, L. M., Katz, S. J., \& Welch, H. G. (1997). Is language a barrier to the use of preventive services? Journal of General Internal Medicine www.bbc.co.uk/health.

Ong, L. M., de Haes, J. C., et al. (1995). Doctor-patient communication: a review of the literature. Social Science and Medicine, 40(7), 903-918.

\section{Copyrights}

Copyright for this article is retained by the author(s), with first publication rights granted to the journal.

This is an open-access article distributed under the terms and conditions of the Creative Commons Attribution license (http://creativecommons.org/licenses/by/4.0/). 